\title{
Environmental DNA Monitoring: Better Tracking of Endangered, Rare, Cryptic, and Invasive Species
}

\section{William M. Ota ${ }^{1,2}$, Caitlyn Hall3,4, John Malloy ${ }^{3,5}$, Morgan A. Clark ${ }^{6}$}

${ }^{1}$ University of California Riverside, Evolution, Ecology, and Organismal Biology Department, Riverside, CA

2University of California Riverside, Center for Science to Policy, Riverside, CA

${ }^{3}$ Arizona State University, Arizona Science Policy Network, Tempe, AZ

${ }^{4}$ Arizona State University, Sustainable Engineering and the Built Environment, Tempe, AZ

${ }^{5}$ Arizona State University, School of Earth and Space Exploration, Tempe, AZ

${ }^{6}$ Colton High School, Science Department, Colton, CA

http://doi.org/10.38126/ISPG170117

Corresponding author: wota001@ucr.edu

Keywords: biodiversity; conservation; California; endangered species; invasive species

Executive Summary: As the global number of endangered, rare, and invasive species continues to increase, legally mandated efforts to monitor species' ranges and abundances have grown exponentially. Human population growth is affecting an increasing number of species that need to be monitored, resulting in difficulties providing necessary data on the abundances, ranges, and movement of these species (Kelly 2014). We currently lack practical monitoring techniques for remote, hard-toaccess habitats and species with low population counts, which makes it difficult to make informed management decisions (Kelly et al. 2014). Biologists use a variety of comprehensive field- and labor-based monitoring techniques including markrecapture studies, depletion surveys, and tracking surveys. Environmental DNA (eDNA) is the genetic material shed by every organism into its surrounding environment, which can then be collected from air, soil, or water and analyzed to assess the composition of species present at a site (Thomsen and Willerslev 2015). eDNA monitoring is a tool that does not require the same man-hours that other techniques require. This allows eDNA to be deployed for biomonitoring, natural resource management, and decision making in ways traditional techniques cannot (Biggs et al. 2015; Kelly et al. 2014). Past use of eDNA in programs, including CaleDNA and the Aquatic eDNA atlas project, demonstrated that eDNA is currently a viable monitoring tool for endangered, rare, cryptic, and invasive species. In 2020, the United States Department of the Interior's National Invasive Species Council Work Plan recognized the potential of eDNA and prioritized its exploration for the first time (United States Department of the Interior, 2020). We believe developing permanent funding sources or amending $\mathrm{AB} 2470$ to include funds for natural resource managers to implement eDNA monitoring programs and information databases is necessary to continue to support societal growth and biodiversity in California. An eDNA monitoring program will allow natural resource managers to better inform land development, conservation, and environmental management decision-making in California. 


\section{The role of eDNA in the current ecological landscape}

Growing human populations have placed a variety of pressures on the natural world, resulting in a humandriven change to our planet's climate, the function of ecosystems, and dispersal rate of species (Elmqvist et al. 2013). Urban and suburban centers, including a developing California, U.S.A. city network, have rapidly increased in size as rural populations have migrated to cities in search of opportunities. These stressors have increased dependence on a global network of natural resources resulting in increased numbers of rare, endangered, and invasive species. To support robust societal growth and preserve global biodiversity, more comprehensive data on the abundances and ranges of species are needed. Rare species include those with low population counts spread over large landscapes (mountain lions or great white sharks). Endangered species are usually rare but are also under threat of extinction (blue whales or cheetahs). Invasive species are causing measurable economic or ecological harm in a location they have been introduced (nutria or quagga mussels). In order to preserve the biodiversity and economic value of ecosystems, we must develop the tools to preserve natural diversity while supporting economic development within California. eDNA has the ability to become an important monitoring tool providing data on primary species that is needed to inform regulatory, permitting, and management decisions within modern, mixed ecological-urban influenced landscapes.

\section{i. Endangered, rare and cryptic Species}

One of the most promising applications of eDNA monitoring is identifying endangered, cryptic (physically similar, but genetically different), and rare species (Cristescu et al. 2018; Garlapati et al. 2019). eDNA analysis is particularly suited for species that live in secluded environments that are hard to reach or that actively avoid human contact (Jerde et al. 2011). Current methods require a team of experts to visually track rare, cryptic, and endangered species in the environment, a time- and labor-intensive endeavor. With eDNA, surveying teams can more quickly identify which sites have traces of the species of interest (Spear et al. 2015). For example, in aquatic riverine ecosystems, areas upstream of a collection location can be assessed through eDNA analysis, thereby lowering the number of locations scientists need to sample. If cryptic species are involved, an additional layer of analysis and monitoring must be done for species identification. eDNA is also particularly suited for differentiating between cryptic species for conservation efforts. The longevity and ability to detect eDNA in the environment is dependent upon a variety of factors including which medium it is collected from, what organism shed the DNA, and what sampling technique is used to collect the eDNA. With the information provided by eDNA, surveying teams can devote resources to locations where there is already evidence of species' presence. This can reduce the chance of misspent time and maximize the conservation resources.

Experts have already demonstrated eDNA's potential for identifying and monitoring endangered, rare, and cryptic species over few sampling events (Closek et al. 2019, Garlapati et al. 2019). While other studies using traditional surveying technologies can only focus on a limited number of species, Closek et al. (2019) were able to identify 65 distinct animal and fish populations that included whales, sharks, and seals over several days of survey study along the 335 miles of the coast of central California. Others have successfully used eDNA techniques to inform management strategies of priority species (i.e., those with declining populations or of ecosystem and socioeconomic importance) in aquatic, terrestrial, and aerial environments (Garlapati et al. 2019). By increasing the amount of available data on critical species and local ecosystems they can be better protected and can facilitate informed management plans and regulatory requirements.

\section{ii. Invasive species}

Species that negatively impact the ecosystems to which they were introduced can be classified as invasive species. As the spread of invasive species is often associated with and facilitated by human activities, it is imperative to elucidate and mitigate the ecological and economic harm they may cause. Invasive aquatic species provide some of the most well-known examples of negative impacts on ecosystems and surrounding human populations. For example, the proliferation of invasive freshwater carp in California and the Mississippi and Illinois Rivers has been demonstrated to have a negative effect on ecosystem health by directly harming native species, indirectly impacting the food chain, and threatening economic resources in invaded areas (Stern et al. 2014, California Department of Fish and Wildlife, 
2020). Projected further spread of these invasive freshwater fish threatens harm to economically valuable commercial fish and recreational use of the habitats in which they live (Kahler et al. 2020). Additionally, the spread of Zebra and Quagga mussel species has been well documented to have extensive negative ecological and economic impacts in freshwater bodies throughout the United States (Wong and Gerstenberger 2011). The further spread of these invasive mussels threatens increased future loss of native wildlife and damage to aquatic infrastructure in California and the western United States (California Department of Fish and Wildlife, 2020). Furthermore, invasive species have been shown to pose indirect harm to human populations by affecting the prevalence of human disease vectors, such as mosquitoes (Bucciarelli et al. 2019).

The spread of invasive species is partly facilitated by the difficulty of tracking their presence, abundance, and potential to spread into new ecosystems (Kamenova et al. 2017). The inability to efficiently track the abundance and spread of invasive species using traditional methods has caused economic and environmental harm, and threatens further damage in the future (Hauser and McCarthy 2009). The use of eDNA monitoring tools provides an efficient, expedited method for assessing the presence and abundance of invasive species and can help prevent their spread into new ecosystems (Kamenova et al., 2017). In this manner, eDNA shed by organisms can be extracted from various habitat types and used to detect, identify, and quantify invasive species presence to better control and eradicate them (Rees et al., 2014). eDNA also provides the ability for early detection of new invasive species in a habitat, which could prove essential for mitigating their ecosystem impacts (Sepulveda et al., 2019). Early detection of invasion events can prevent increased economic costs associated with mitigation, containment, and eradication of invasive species once they are well established (Sepulveda et al., 2019). Additionally, eDNA provides increased sensitivity to the detection of invasive species. Increased sensitivity decreases the need for surveyors to observe invasive species presence first-hand via traditional sampling methods, thus offering a more efficient assessment of species presence (Dejean et al. 2012). Invasive species are a pervasive and increasing threat to the ecological and economic benefits of our ecosystems, and the implementation of eDNA surveying techniques will provide a more effective method of monitoring and mitigating the damage they create.

\section{II. eDNA monitoring benefits all stakeholders in California}

The adoption of eDNA techniques is expected to result in benefits for all stakeholders, including developers, agencies, conservationists, various industry members, and all Californians in the community. Developers and advocates for increased housing and public infrastructure criticize the California Environmental Quality Act and its requirement for environmental investigation and an environmental impact report, finding it to be costly and a significant source of project development delays (BAE Urban Economics, 2016). By implementing eDNA as a survey technique, time and money can be saved by eliminating the need to repeat site investigations unexpectedly during a project's timeline (Biggs et al. 2015). The robustness of eDNA results may mitigate litigation costs following the completion of a project because the site's environmental status will be better known.

Through mapping with eDNA, stakeholders will possess a more robust understanding of a site's biodiversity both spatially and temporally (Thomsen et al. 2015). Further, collaborating with academic eDNA collection efforts can reduce oversampling at a specific location and leverage existing knowledge to develop government-run eDNA operations and inform policy. Upon the development of an eDNA library, eventual resource allocation for surveying and analysis can be reduced. This broad eDNA mapping effort can help state-level regulatory and permitting agencies be better informed and require fewer resources. For construction or community development, knowing the expected environmental impact earlier can inform study plans and permitting (14 CCR § 15063, 15064).

Conservation efforts are better able to focus on sites that are likely to have critical or priority species and improve management plans. As a result, awareness facilitated by using eDNA can lead to reducing the economic and environmental impact of invasive species and protecting endangered species through early detection.

eDNA highlights the breadth of species critical to an environment. Greater awareness from research can 
enable better decision-making for industry. For example, information provided about popular industrial fishing locations (e.g., salmon and trout) (Garlapati et al. 2019) can promote business development through sustainable fishing practices. Others have demonstrated the potential for using eDNA to improve public health by monitoring the viral and bacterial presence and movement within the environment (Garlapati et al. 2019). With the information provided by eDNA, various stakeholders can work preemptively to address a site's needs and lessen cost and resource burdens, while promoting conservation, to meet collective needs and legal requirements.

\section{The implementation of eDNA libraries}

Increased use of eDNA will require additional space, equipment, and labor within California agencies to store and analyze these samples. The technical investment will ultimately lead to greater efficiency in collecting, analyzing, and interpreting samples compared to traditional methods of detecting species. Additionally, this investment will allow for future expansions of eDNA libraries with limited updates, thereby reducing future time and labor costs. This expansion and implementation of eDNA libraries requires a three-step process:

1) Storage for eDNA samples must be created;

2) Analysis capability of laboratories must be increased as eDNA becomes a more viable and popular option; and,

3) These publicly funded eDNA analyses must be made freely accessible to scientists and constituents.

The eDNA samples contain DNA from a variety of species, some of which may have never been previously discovered. Techniques in DNA sequencing are becoming increasingly comprehensive in identifying species (Ji et al. 2013), however, as technology continues to advance, older samples will need to be re-analyzed to find data that may have been missing when outdated sequencing technology was used. This is analogous to re-opening a cold case based on new DNA evidence. To that end, natural-resource laboratories in California must expand their DNA sequencing and sample storage capacity.
In addition, the data generated must be made publicly available for decision-makers, scientists, and other interested constituents. An existing model from the Upper Midwest Environmental Sciences Center (UMESC) links cloud-based storage of eDNA samples across a large portion of the United States. Through leveraging existing state coalitions, the eDNA data generated in California should be incorporated into this existing framework, allowing for public access to this essential information.

\section{i. Technological limitations and concerns}

Barriers to the increased use of eDNA within the public sphere include concerns surrounding the rate of false positives/negatives, the rate at which eDNA samples can be analyzed after being collected, and current management community skepticism about eDNA's efficacy and place in a biomonitoring framework (Cristescu and Hebert 2018; Thomsen and Willerslev 2015a; Kelly et al. 2014). In addition, the technology needed to sequence DNA quickly and effectively is consistently improving (Heather and Chain 2016).

To address these concerns, funding should be allocated for periodic updates in sequencing technology in order to maintain eDNA monitoring and analysis as one of the best long-term management tools. eDNA is used to address conservation issues across the nation (Boussarie et al. 2018), and a similar implementation can be adopted in California. Additionally, the cost of sequencing DNA has dramatically decreased from over $\$ 10,000$ to $\$ 0.01$ per 1000 bases over the past two decades. This cost continues to decrease due to improved technology. To lessen the cost of analysis and potential backlog of collected eDNA samples, additional lab technicians should be hired and periodic updates to existing sequencing technology should be performed. These steps will take advantage of the lowered cost of sequencing and reduce the potential backlog of eDNA samples. Additionally, the implementation of eDNA is still an emerging science. The broader implementation of this tool, and the technological advances which will occur as a result of this widespread usage, will allow for the alleviation of concerns regarding false positives/negatives and other methodology considerations. The scientific community sees eDNA as an accurate and precise tool, and its application to the broader California community will back up this claim. 


\section{Policy recommendation}

The decreased cost of genetic analyses has enabled modern eDNA techniques to increase available primary species data for a wide range of ecologically and economically important species. The development of eDNA pipelines and their inclusion in existing monitoring programs will enable natural resource managers to better monitor and track the abundances, ranges, and movements of species (Figure 1). Governmental agencies within California, including the California Department of Fish and Wildlife, the California Department of Water Resources, and the Invasive Species Council of California are all positioned to immediately leverage this emerging technology to better protect biodiversity in the state. The development of eDNA based monitoring programs and libraries will increase the efficiency of biological monitoring and provide necessary data for management decisions. The Aquatic eDNAtlas, managed by the U.S. Forest Service, provides an example of how governmentally coordinated eDNA data libraries guide decision making and enable effective conservation and management. Without changes to the status quo programs, current delays in the completion of environmental impact reports, mitigation projects, invasive species removals and the extinction of endangered species will continue to accelerate. eDNA based monitoring methods will decrease the time and effort needed to conduct necessary biological monitoring for all of the above purposes. Implementing this technology now will ensure monitoring needs are met before they outstrip the ability of agencies and other scientists to provide the necessary labor. By providing funding for eDNA monitoring throughout California, the state will increase the efficiency of crucial species data collection.

Prior programs including CALeDNA, run by the University of California systems, and the Aquatic eDNAtlas have failed to comprehensively address the need for increased biological monitoring due to a lack of continued support and utilization. This is due primarily to the short-term investments that fund these programs that were not renewed or expanded. In order to fund the proposed expansion of eDNA monitoring within California, we have identified two possible strategies:

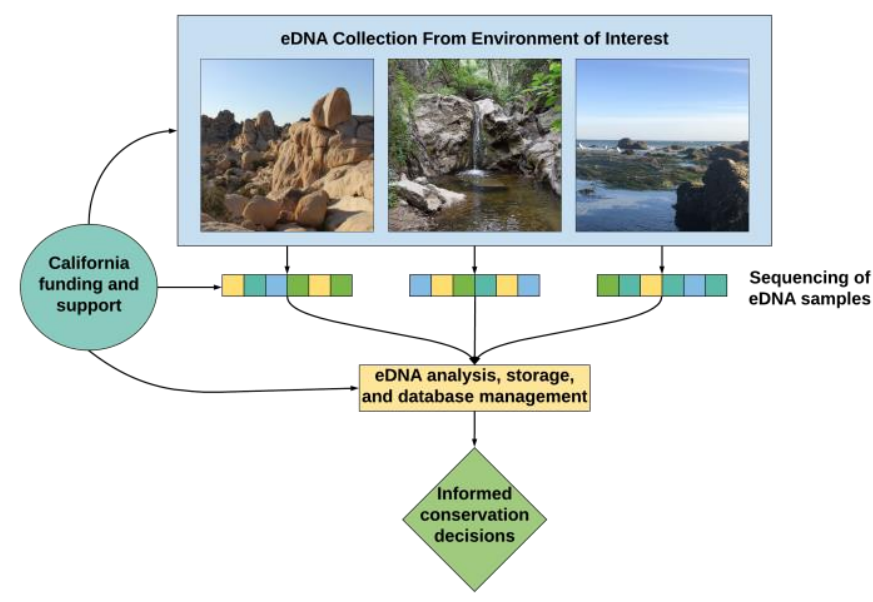

Figure 1: California funding and support for eDNA monitoring will sustain an analytical program that can inform management and conservation decisions. Improved primary data on the distribution of these important classifications of species will have positive impacts on biodiversity and development within the state.

- The first would consist of an amendment to AB 2470 (Invasive Species Council of California, Sec. 3. 7702) through which funding could be permanently appropriated for eDNA monitoring through the Invasive Species Account. These funds would then be managed by the Invasive Species Council of California and disbursed to fund eDNA monitoring in order to prevent the spread of invasive species. If this program is successful, it could be expanded to incorporate monitoring of rare and endangered species using the same sampling network.

- The second identified funding stream could be the use of funds from Props 1 and 68, which authorize the disbursement of funds for ecosystem restoration and protection projects. This measure would provide a onetime funding stream that could be administered through natural resource agencies in California. Upon the completion of initial eDNA monitoring programs, a longterm source of funding and administrative home needs to be established in order to administer a permanent government-run California eDNA program.

Development should be directed towards achieving long-term funding, as detailed in option 1, for an eDNA species monitoring program. These funds would be used to sustain a monitoring network 
similar to existing frameworks in state and federal wildlife agencies. Funding for a long-term eDNA monitoring program must address needs for storage, technicians, equipment, and facilities to maintain a practical, high-quality genomic database.

\section{Conclusion}

eDNA has already been shown to be a successful monitoring tool for a variety of endangered, rare, cryptic, and invasive species, informing conservation and management decisions. If the use of eDNA methods is not employed to monitor and mitigate invasive species impacts, we risk the increased spread of invasive species to new areas and the worsening of negative ecological and economic consequences in areas already harmed by invasion. The continued survival and protection of endangered and rare species also depends on better data on these species' abundances, ranges, and movements for both conservation and legal purposes. Scientists and agencies are faced with pressures from environmental regulations, natural resource managers, conservationists, and businesses to

\section{References}

Biggs, J., Ewald, N., Valentini, A., Gaboriaud, C., Dejean, T., Griffiths, R. A., Foster, J., et al. 2015. "Using EDNA to Develop a National Citizen Science-Based Monitoring Programme for the Great Crested Newt (Triturus Cristatus)." Biological Conservation 183: 19-28. https://doi.org/10.1016/j.biocon.2014.11.029.

Boussarie, G., Bakker, J., Wangensteen, O. S., Mariani, S. Bonnin, L., Juhel, J. B., Kiszka, J. J. et al. 2018. "Environmental DNA Illuminates the Dark Diversity of Sharks." Science Advances 4 (5): eaap9661. https://doi.org/10.1126/sciadv.aap9661.

Bucciarelli, G. M., Suh, D., Lamb, A. D., Roberts, D., Sharpton, Shaffer, H. B., Fisher, R. N., \& Kats. L. B. 2019. "Assessing Effects of Non-Native Crayfish on Mosquito Survival." Conservation Biology 33 (1): 122-31. https://doi.org/10.1111/cobi.13198.

"California's Invaders." n.d. Accessed July 23, 2020. https://wildlife.ca.gov/Conservation/Invasives/Spe $\underline{\text { cies }}$

Closek, C. J., Jarrod A. S., Starks, H. A., Schroeder, I. D., Andruszkiewicz, E. A,. Sakuma, K. M. Bograd, S. J., Hazen, E. L. Field, J. C. \& Boehm. A. B. 2019. "Marine Vertebrate Biodiversity and Distribution Within the Central California Current Using Environmental DNA (EDNA) Metabarcoding and Ecosystem Surveys." Frontiers in Marine Science 6 (December): 732. https://doi.org/10.3389/fmars.2019.00732. conduct increasing amounts of biological monitoring. Due to current lack of tools needed to locate and identify organisms in a more efficient manner, biological monitoring has been carried out inefficiently and in a time-consuming and primarily labor-intensive way. Today we need precise tools that decrease the time and cost of biological monitoring efforts and enable experts to focus on key areas of need. Rapid, sensitive, and cost-effective eDNA monitoring will enable the protection of habitat integrity and will better prevent economic harm in the future. Providing funding and an opportunity to use eDNA will benefit conservationists, businesses, and the scientific community. These groups will have the ability to produce better wildlife and natural resource stock assessments, focus resources on removal and conservation efforts, improve habitat preservation, and decrease monitoring time and cost. If eDNA monitoring ends primary data as a limiting factor in the natural resource decision-making process, we can better utilize time, funds, and effort in natural resource management.

Cristescu, M. E., and Hebert, P.D.N. 2018. "Uses and Misuses of Environmental DNA in Biodiversity Science and Conservation." Annual Review of Ecology, Evolution, and Systematics 49 (1): 209-30. https://doi.org/10.1146/annurev-ecolsys-110617$\underline{062306 .}$.

Dejean, T., Valentini, A., Christian M., Pierre T., Bellemain, E, \& Claude M. 2012. "Improved Detection of an Alien Invasive Species through Environmental DNA Barcoding: The Example of the American Bullfrog Lithobates Catesbeianus." Journal of Applied Ecology 49 (4): 953-59.

https://doi.org/10.1111/j.13652664.2012.02171.x.

Department of the Interior, Us. 2020. "U.S. Department of the Interior 2019/2020 Annual Performance Plan \& 2018 Report."

https://www.doi.gov/sites/doi.gov/files/uploads/d oi final appr 2019-2020.pdf

Elkind, E., Hecht, S. B., Selmi, D. P., Professor of Law, Loyola Law School, Janet Smith-Heimer, Mba BAE President Jessica Hitchcock, MCP BAE Vice President Paige Roosa, MCP BAE Associate Chelsea Guerrero, and MCP BAE Associate. 2016. "CEQA in the 21st Century."

www.bae1.comwww.mash-production.com. 
Elmqvist, T., Fragkias, M., Goodness, J., Güneralp, B., Marcotullio, P. J., McDonald, R. I., Parnell, S., et al. 2013. "Stewardship of the Biosphere in the Urban Era." In Urbanization, Biodiversity and Ecosystem Services: Challenges and Opportunities: A Global Assessment, 719-46. Springer Netherlands. https://doi.org/10.1007/978-94-007-7088-133.

Garlapati, D., Charankumar, B., Ramu, K., Madeswaran, P., and Murthy, M. V. R. 2019. "A Review on the Applications and Recent Advances in Environmental DNA (EDNA) Metagenomics." Reviews in Environmental Science and Biotechnology. Springer Netherlands. https://doi.org/10.1007/s11157-019-09501-4.

Hauser, C. E., \& McCarthy, M. A. 2009. "Streamlining 'Search and Destroy': Cost-Effective Surveillance for Invasive Species Management." Ecology Letters 12 (7): 68392. https://doi.org/10.1111/j.14610248.2009.01323.x.

Heather, J. M., and Chain, B. 2016. "The Sequence of Sequencers: The History of Sequencing DNA." Genomics. Academic Press Inc. https://doi.org/10.1016/j.ygeno.2015.11.003.

Jerde, C. L., Andrew R. M., Chadderton, L. P., and Lodge, D. M., 2011. "'Sight-Unseen' Detection of Rare Aquatic Species Using Environmental DNA." Conservation Letters 4 (2): 150-57.

https://doi.org/10.1111/j.1755263X.2010.00158.x.

Yinqiu, J., Ashton, L., Pedley, S. M., Edwards, D. P., Tang, Y., Nakamura, A., Kitching, R., et al. 2013. "Reliable, Verifiable and Efficient Monitoring of Biodiversity via Metabarcoding." Ecology Letters 16 (10): 1245-57. https://doi.org/10.1111/ele.12162.

Kahler, J. S., Liu, R.W., Newcomb, T, J., Herbst, S, and Gore, M. L. 2020. "Public Risk Perceptions Associated with Asian Carp Introductionand Corresponding Response Actions." Management of Biological Invasions $11 \quad$ (1): 80-95. https://doi.org/10.3391/mbi.2020.11.1.06.

Kamenova, S, T J Bartley, D Bohan, J R Boutain, R I Colautti, I Domaizon, C Fontaine, et al. n.d. "Invasions Toolkit: Current Methods for Tracking the Spread and Impact of Invasive Species." Accessed July 23, 2020. https://doi.org/10.1016/bs.aecr.2016.10.009.

Kelly, R. P. 2014. "Will More, Better, Cheaper, and Faster Monitoring Improve Environmental Management?" SSRN Electronic Journal, 1111-47. https://doi.org/10.2139/ssrn.2408550.
Kelly, R. P., Port J. A., Yamahara, K. M., Martone, R. G., Lowell, N., Thomsen, P. F., Mach, M. E. et al. 2014. "Harnessing DNA to Improve Environmental Management." Science 344 (6191): 1455-56. https://doi.org/10.1126/science.1251156.

“Quagga and Zebra Mussels.” n.d. Accessed July 23, 2020. https://wildlife.ca.gov/Conservation/Invasives/Qua gga-Mussels.

Rees, H. C., Maddison, B. C., Middleditch, D. J., Patmore J. R.M. and Gough, K. C., 2014. "The Detection of Aquatic Animal Species Using Environmental DNA - a Review of EDNA as a Survey Tool in Ecology." Journal of Applied Ecology. Blackwell Publishing Ltd. https://doi.org/10.1111/1365-2664.12306.

Sepulveda, A. J., Schmidt, C., Amberg, J., Hutchins, P., Stratton, C., Mebane, C., Laramie, M. B., and Pilliod. D. S. 2019. "Adding Invasive Species Biosurveillance to the U.S. Geological Survey Streamgage Network." Ecosphere 10 (8).

https://doi.org/10.1002/ecs2.2843.

Spear, S. F., Groves, J. D., Williams, L. A., and Waits, L. P. 2015. "Using Environmental DNA Methods to Improve Detectability in a Hellbender (Cryptobranchus Alleganiensis) Monitoring Program." Biological Conservation 183: 38-45. https://doi.org/10.1016/j.biocon.2014.11.016.

Stern, C. V., Upton, H. F., \& Brougher, C. 2014. "Asian Carp and the Great Lakes Region Specialist in Natural Resources Policy." www.crs.gov.

Thomsen, P. F., \& Willerslev, E. 2015. “Environmental DNA - An Emerging Tool in Conservation for Monitoring Past and Present Biodiversity." Biological Conservation. $\quad$ Elsevier Ltd. https://doi.org/10.1016/j.biocon.2014.11.019.

Ventura, L. De, Kopp, K., Seppälä, K., \& Jokela, J. 2017. "Tracing the Quagga Mussel Invasion along the Rhine River System Using EDNA Markers: Early Detection and Surveillance of Invasive Zebra and Quagga Mussels." Management of Biological Invasions 8 (1): 101-12. https://doi.org/10.3391/mbi.2017.8.1.10.

Wong, W. H., \& Gerstenberger, S. L. 2011. “Quagga Mussels in the Western United States: Monitoring and Management." Aquatic Invasions 6 (2): 125-29. https://doi.org/10.3391/ai.2011.6.2.01.

William Ota (he/him) is the current Government Relations Chair and former Executive Chair of the UC Riverside Center for Science to Policy (S2P). As a PhD student in the department of Evolution, Ecology, and Organismal Biology at UC Riverside he studies how the effects of wastewater discharge are altering the lives of native species in urban rivers. This research will help us protect native species and ecosystems and preserve them for future generations. In order for his research to have broad impacts he collaborates with local water districts, conservation districts, and United States Geological 
Surveys. In his free time William enjoys SCUBA, houseplant propagation, and building terrariums. Email: wota001@ucr.edu

Caitlyn Hall (she/her/they/them) is a founding member of the Arizona Science Policy Network and a PhD student in Environmental Engineering at Arizona State University. Her current research promotes climate change and natural hazard resilience in communities using microbes to reduce damage from earthquake-induced liquefaction. She works with industry, community, and government leaders to develop best-fit technical, policy, and public health solutions to best-address a community's challenges and values. Her other research has focused on soil and water remediation, and sustainable use of resources for urban and greenhouse crop production and agriculture. For fun, Caitlyn spends her time rock climbing and trail running.

John F. Malloy (he/him) is a PhD candidate studying Astrobiology and Complex Systems Science at Arizona State University. He studies the fundamental nature and definition of life, both on Earth and on other planets, through exploring the evolution of life and life-like systems. He is working to predict future evolutionary steps and create a universal definition of evolution. He is also a member of the Arizona Science Policy Network, where he works to advance science-based policy measures in Arizona. He enjoys training for and competing in ultramarathons across the American Southwest.

Morgan Clark (she/her) is a Biology Teacher at Colton High School. As an educator she aims to equip her students with science communication skills so that they may advocate for the preservation of ecosystems in their communities. Before she accepted her current role, she was a Laboratory Manager and Research Assistant at Pepperdine University where she published work on the effects of climate change on California newts. In her free time, she enjoys collecting field guides and creating digital art.

\section{Acknowledgements}

The authors would like to acknowledge the guidance and support of Kevan Yamahara from the Monterey Bay Aquarium Research Institute, Doug Brown from the UC Riverside Center for Science to Policy, and Susan Hackwood from the UC Riverside Center for Science to Policy. 